\title{
Leopoldo Panero y su antología de poesía hispanoamericana. Una lectura "personal" de América
}

\author{
Antonio RIVERO MACHINA \\ Universidad de Extremadura \\ antoniorm@unex@.es
}

\begin{abstract}
RESUMEN
El presente artículo trata de ofrecer una lectura estética y política de la Antología de la poesía hispanoamericana que publicara Leopoldo Panero entre 1944 y 1945 bajo protección gubernamental. Para ello se parte de la particular biografía del escritor astorgano, su relación en los años treinta con los poetas hispanoamericanos -especialmente Vallejo y Neruda- y su gira por América ya como supuesto prohombre del régimen franquista en 1949 y 1954 . La lectura sistemática de sus prólogos y selección de poetas revela la particular visión de Panero sobre Hispanoamérica, mediatizada por el concepto imperial de Falange pero formulada bajo su propia visión de lo que la lírica americana representa para la lengua castellana. Se sostiene así en estas líneas la tesis de que los postulados de Panero representan, a pesar de todo, una opción mucho más compleja de lo que se suele considerar.
\end{abstract}

Palabras clave: Leopoldo Panero, Poesía hispanoamericana, Franquismo e Hispanoamérica, Poesía española de posguerra.

\section{Leopoldo Panero and his antology of the Spanish American Poetry. A "personal" reading of America}

\begin{abstract}
The current article tries to offer an estetic and political lecture of the Antología de la poesía hispanoamericana published by Leopoldo Panero between 1944 and 1945 under the governmental protection. The article starts defining the particular biography of the spanish writer, and his relations with the Spanish American poets -specially Vallejo and Nerudaand his journeys to America as a relevant man of the Francoist movement between 1949 and 1954. The systematic lecture of his prefaces and his selection of poets disclose his particular vision of Latin America, always influenced by the imperial concept of Falange but based in his own vision of the symbolism of the American Lyric. These lines try to maintain, to summarize, the thesis that defends the incredible complexity of Panero's postulates.
\end{abstract}

Key words: Leopoldo Panero, Latin American poetry, Francoism and Latin America, Spanish postwar poetry. 
SUMARIO: 1. Introducción 2. Leopoldo Panero e Hispanoamérica desde lo "personal" 3. La reconstrucción cultural de Escorial y la llamada "política de la hispanidad" 4. Una lectura estética de Hispanoamérica con fecha de 1945.

\section{Introducción}

Frecuentemente se destaca la íntima relación establecida entre el mensaje estético y político de los jóvenes escritores del llamado "Grupo Escorial" y la lectura heroica e imperialista propuesta por el ideario de Falange, inmediatamente asumida por el franquismo más temprano. Esta "estetización" de la política, de inspiración joseantoniana, fue decisivamente formulada por Ernesto Giménez Caballero en su libro Arte y Estado en 1935, un año antes de la sublevación del llamado "Bando Nacional". Con la publicación en 1940 y 1943 por la gubernamental Editora Nacional de la antología que Luis Felipe Vivanco y Luis Rosales realizaron bajo el grandilocuente rótulo de Poesía heroica del Imperio sobre la poesía renacentista y barroca española cristalizó un proyecto cultural de interpretación y reinterpretación del legado histórico hispánico de mano de dos de los mejores miembros de la joven intelectualidad del nuevo régimen. Sin desdecir la perspectiva personal de cada uno de ellos, Vivanco y Rosales ofrecían una misma lectura estética y política de nuestra literatura áurea. Un año más tarde, le llegó el turno a Leopoldo Panero. Igualmente sin menoscabo de una relativa autonomía como antólogo, el poeta astorgano asumió un proyecto claramente emparentado con el anterior. La Editora Nacional encargó a Panero, en esta misma senda, la preparación de una Antología de la poesía hispanoamericana que finalmente sería publicada en dos volúmenes en cuarto en 1944 y 1945. No se suele destacar la filiación entre ambas antologías y, sin embargo, funcionan en un mismo sentido político y estético. En ambos títulos se puede hallar la clave para comprender los derroteros propuestos por aquella joven intelectualidad elegida por el régimen franquista para reconstruir $-\mathrm{y}$ redirigir- la creación literaria y artística del país, tan maltrecha tras la aún humeante Guerra Civil.

Para este análisis cerrado y minucioso de la labor crítica y antológica desempañada por el poeta leonés -en claves política y estética muy concretas-, así como de la continuidad editorial entre este proyecto y la más citada antología de Rosales y Vivanco, se hace necesario enmarcar la Antología de la poesía hispanoamericana de Leopoldo Panero en un triple contexto: personal, político y estético. La publicación de esta antología no supone sino un hito más -acaso menor e intermedio en su evolución hacia la publicación en 1953 de Canto personal-en su estrecha implicación con el continente americano, con su arte en general y con su literatura en particular. Algunos de estos episodios, como su fervorosa amistad hacia César Vallejo y declarada admiración hacia Pablo Neruda en tiempos de la Segunda República, se contraponen antitéticamente $-\mathrm{y}$ con frecuencia de manera maniquea- con su imagen de embajador cultural del franquismo desde la dirección de las Bienales Hispanoamericanas de Arte o como defensor de la leyenda rosa en 
su polémica contra el citado nobel chileno a raíz de su Canto general, allá por los primeros años de la década de los cincuenta. No es este un terreno inexplorado para la crítica, sobre cuyos matices y grises se ha llamado igualmente la atención (Cabañas, 2007). Sin embargo, tal vez quede una deuda pendiente con esa antología que el astorgano realizara en el ecuador de ambos extremos o versiones políticas de sí mismo. Un ecuador tanto ideológico como cronológico. Sencillamente, se suele considerar dicha antología como un mero gozne, como el primer paso hacia la redención y reconversión para la diplomacia cultural franquista de tan valioso poeta. Sin embargo, estos dos volúmenes editados en el epicentro de la década de los cuarenta albergan en sí mismos un valiosísimo interés propio, digno de ser estudiado.

\section{Leopoldo Panero e Hispanoamérica desde lo "personal"}

La elección de Panero para antologar la lírica americana en español no fue nada casual. Su proximidad a la poesía del otro lado del Atlántico fue una inclinación personal desde sus primeros escarceos con la literatura. Ricardo Gullón, en su biografía del Panero joven, recuerda cómo "la entrada en la adolescencia implicó la entrada en la poesía, de la mano de Rubén Darío" (Gullón, 1985: 21). Precisamente, es el insigne vate nicaragüense el eje vertebrador de su propia antología para la lírica americana. Pocos años después, esta relación con los poetas hispanoamericanos se hará tangible y directa con el propio acceso del joven Leopoldo a los círculos literarios madrileños de los primeros años treinta.

El rehermanamiento de las literaturas hispanoamericanas y española venía consolidándose desde la celebración del IV Centenario en 1892 y el espectacular influjo ejercido por Rubén Darío en los poetas peninsulares. Desde entonces y hasta 1939, en esa franja temporal que Mainer bautizó hace ya algunos años como "Edad de Plata", el trasiego de escritores hispanoamericanos, jóvenes y prometedores o consagrados y reverenciados, es constante y determinante para la literatura española misma. Madrid se convierte, a su vez, en centro difusor de nuevos libros de autores como José Asunción Silva, José Santos Chocano, Amado Nervo o José Enrique Rodó. Visitan ampliamente nuestro país firmas como las de José María Arguedas, Roberto Arlt, Jorge Luis Borges, Alfonso Reyes o Pedro Henríquez Ureña, tan seguido por Leopoldo Panero en su estudio sobre la poesía hispanoamericana. Aunque menos destacados en los resúmenes académicos españoles, otros poetas fueron igualmente determinantes para el bullir de la joven literatura de los años treinta en la que nuestro antólogo astorgano se movió como miembro de pleno derecho. Visitaron Madrid, o publicaron en dicha ciudad, al mediar la década de los treinta, una amplia nómina de poetas hoy menos estudiados. Algunos de ellos, aún entusiastas del creacionismo y el ultraísmo, son Ricardo E. Molinari, Raúl González Tuñón, José González Carbalho, Miguel Ángel Gómez, Ángel Cruchaga Santa María, Luis Enrique Délano o el cubano Félix Pita Rodríguez. Con todos ellos compartirá páginas Leopoldo Panero en Caballo verde para la poesía (Barrera, 
2005: 20). En cualquier caso, tres son los grandes poetas, por su influjo y por su impacto, que visitan España en aquellos años: Vicente Huidobro, César Vallejo y Pablo Neruda. Los tres ejercieron una tremenda influencia sobre el aún poeta en ciernes Leopoldo Panero.

La huella de Huidobro es detectable en los primeros poemas publicados por el poeta leonés. De clara inspiración creacionista, ultraísta y superrealista son sus primeros poemas, publicados entre 1928 y 1932, especialmente desde publicaciones como Brújula y Nueva Revista, esta última cofundada por el astorgano junto a otros jóvenes tan prometedores como él -José Antonio Maravall, José Antonio Muñoz Rojas y José R. Santeiro- ${ }^{1}$ Precisamente en Nueva Revista Leopoldo ofrece "una defensa encendida de Huidobro" (Trapiello, 1995: 96). Pero si el magisterio poético del autor de Altazor trazó la senda de partida para sus primeros versos publicados, la figura de César Vallejo dejará una huella indeleble en Panero. Su persona y su obra se convirtieron pronto en un objeto casi de culto y reverencia íntima, imposibles de disimular en el astorgano. En aquel Madrid de 1931, Leopoldo se convierte en uno de sus admiradores, que tan atentos le escuchan en la tertulia de la Granja El Henar. Asume el poeta leonés el comunismo cristiano propugnado por el autor de Trilce, colocándose en la solapa de su chaqueta -inevitable hacerse eco de este ya lugar común en toda aproximación biográfica a Panero- una insignia con la hoz y el martillo. La amistad entre Vallejo y Panero es tan sincera y humana como ellos mismos, hasta el punto de que el insigne peruano acompaña a su nuevo amigo en las vacaciones navideñas de 1931, alojándose en la casa familiar de los Panero en Astorga durante unos días.

Tampoco escatimó elogios y admiraciones el astorgano a la llegada de Pablo Neruda. En 1934 el diplomático chileno recala como cónsul en Barcelona, pasando poco después a la embajada de Madrid. Empeñado en catalizar en su persona el abigarrado e inestimable ambiente literario de la capital española, Neruda logra despertar la admiración de nuevos -y no tan nuevos- valores, a los que promocionó hábilmente desde la nueva revista madrileña de Altolaguirre, Caballo verde para la poesía, cuya dirección recayó en el chileno. Los hermanos Panero, Juan y Leopoldo, ${ }^{2}$ se cuentan junto a los Miguel Hernández, Arturo Serrano Plaja, José Antonio Muñoz Rojas o Rosa Chacel, sin faltar Luis Rosales y Luis Felipe Vivanco, como admiradores del autor de Crepusculario. Tampoco los consagrados del Veintisiete -Cernuda, Lorca, Aleixandre, Salinas, Alberti, Guillén- evaden su influjo o amistad. De aquellos años inmediatamente anteriores al

\footnotetext{
${ }^{1}$ Recientemente ha sido publicada una cuidada edición facsímil de la publicación: Nueva Revista. Notación literaria (Madrid, 1929-1930), Gabriele Morelli (ed.), Sevilla, Renacimiento, 2012.

${ }^{2}$ En el primer número de Caballo verde para la poesía, en octubre de 1935, publica Leopoldo su poema "Por el centro del día".
} 
desencadenamiento de la Guerra Civil española quedará el poso de una amistad mutua, honesta y sincera, entre ambos. La contienda posicionará a Panero, a costa de un profundo trauma personal, en el bando opuesto al de Neruda, lo que resultará inaceptable para el nobel chileno.

Sus amistades -intelectuales y comunistas en gran medida-, sumadas a la fama de izquierdistas ganada en Astorga por los tertulianos del Café Universal, entre los que Panero se contaba, llevaron a nuestro protagonista al calabozo una vez estallada la sublevación militar y con Castilla la Vieja en manos de los rebeldes. El fusilamiento de Leopoldo era inminente, y solo el lejano parentesco entre el poeta y Carmen Polo, esposa del propio Francisco Franco, evitó el fatídico "paseo". Aquellos casi tres años ignominiosos de 1936 a 1939 fracturaron traumáticamente el decurso vital de un Panero al que la muerte de su hermano Juan en un accidente de automóvil en agosto de 1937 acabó por conmocionar. De esta manera, el 1 de enero de 1940 no comenzaba para el que sería autor de Escrito a cada instante una década fácil. Salvada la vida, tanto él como su familia, señalada a lo largo de toda la guerra por su parentesco con el eminente republicano Justino de Azcárate, afrontaban una precaria situación económica y social, inimaginable antes de la guerra. Brillante licenciado en Derecho, acreditado políglota -perfeccionados su francés e inglés en Poitiers y Cambrige respectivamente- y potencial diplomático de altura, no tardaría el régimen en reclutar para las labores político-culturales más sutiles a semejante talento. No obstante, al comienzo de aquella década de la autarquía Leopoldo aún mantenía un expediente abierto en la Dirección General de Seguridad como sospechoso político. Es la amistad de la más valiosa intelectualidad del entorno falangista y su nueva revista Escorial el verdadero salvoconducto del astorgano en esos primeros años. La tertulia del café Lyon, la academia Musa Musae -fundada por José María de Cossío e impulsada por Manuel Machado y Gerardo Diego- y la entregada amistad de intelectuales y prohombres del "Movimiento" como Eugenio D'Ors, Antonio Tovar, Dionisio Ridruejo o, especialmente, Luis Rosales y Luis Felipe Vivanco, insertan a Leopoldo Panero en el epicentro del depurado -y tan mermado- parnaso nacional.

Sus influyentes amistades logran sacar del apuro económico más acuciante al poeta leonés con el encargo, en 1941, de una antología amplia y ambiciosa de toda la poesía hispanoamericana escrita hasta la fecha. El proyecto llega desde la Editora Nacional, en manos de Falange y heredera directa de la revista pamplonesa Jerarquía. Unos meses antes sale a la luz el primer tomo de otra antología emblemática para aquellos jóvenes poetas de Escorial, la tan citada Poesía heroica del Imperio. El encargo de la antología hispanoamericana concede al astorgano así un respiro económico e institucional, ${ }^{3}$ al tiempo que le hace retomar su nunca

${ }^{3} \mathrm{Su}$ esposa Felicidad Blanc recuerda en sus memorias que fue el adelanto por este encargo lo que les permitió contraer matrimonio un 29 de mayo de 1941 (Blanc, 1977: 135). 
abandonado contacto con la poesía del otro lado del Atlántico. El trabajo fue escrupulosamente cumplido y en 1944 sale el primer volumen, publicándose el segundo tomo al año siguiente.

La "reconversión" de Panero en activo cultural de referencia para el régimen de Franco dará un nuevo paso con la elección del leonés en 1947 para trabajar en el nuevo Instituto de España en Londres. A pesar de verse acusado de contactos sospechosos con algunos exiliados en Inglaterra, entre los que sobresale Luis Cernuda -muy próximo al matrimonio Panero-Blanc aquellos meses-, no debió de dejar del todo descontenta a la oficialidad franquista ya que en 1949 comienza su labor más importante como embajador cultural del régimen. Su campo de acción no podría ser otro que Hispanoamérica. Ante el bloqueo internacional ejercido sobre España tras el final de la Segunda Guerra Mundial, la figura de Leopoldo Panero, junto a la de otros como Rosales, Foxá o Zubiaurre, fue llevada al continente hermano "contrarrestando con ello la extendida percepción de una actualidad de pobreza cultural, que empezó a prosperar en el extranjero tras la guerra civil, alimentada también por la acción de los exiliados españoles" (Cabañas, 2011: 699). El compromiso del autor de Escrito a cada instante -con cuya publicación en 1949 recibiera el Premio Nacional de Literatura, ya plenamente institucionalizado como "poeta del régimen"- en aquel proyecto de hermanamiento o, por mejor decir, apadrinamiento cultural con América será total en el primer lustro de los años cincuenta a través de su cargo como director de las Bienales de Arte Hispanoamericano. En ese contexto surgirá la famosa disputa con Neruda y su Canto general a través de la publicación, en 1953, de su también premiado Canto personal: carta perdida a Pablo Neruda.

\section{La reconstrucción cultural de Escorial y la llamada "política de la hispanidad"}

Pasado el año de 1939, la relación de Leopoldo Panero con la cultura hispanoamericana dejará de ser electa y natural para verse directamente mediatizada por su condición de sospechoso político, primero, y prohombre del régimen, después. El movimiento americanista español, dibujado en sus líneas maestras por Ángel Ganivet y su Idearium español, era ya una vieja aspiración del regeneracionismo más institucional. No obstante, el americanismo franquista encontrará su precedente directo en el matiz paternalista y espiritual dado al asunto por la dictadura primorriverista.

En esta senda, la lectura reaccionaria del panhispanismo encuentra en los años treinta dos áreas diferentes de formulación, coincidentes en buena parte de sus presupuestos. En torno a la conservadora revista Acción española surge una lectura de la hispanidad de marcado integrismo católico. Con Ramiro de Maeztu como

Los testigos de la boda fueron Manuel Machado, Gerardo Diego, Luis Felipe Vivanco y Luis Rosales. 
articulista estrella en el asunto, en esta publicación -germen del posteriormente llamado "nacionalcatolicismo"- cristalizó la noción providencialista de España como misionera y defensora del mensaje católico en todo el mundo. ${ }^{4}$ A ello se sumaba una regresiva nostalgia por el pasado imperial de España, teniendo el siglo XVI y su simbología como modelo a restaurar. Como segundo pivote ideológico encontramos la lectura que el fascismo español hizo de la perdida grandeza imperialista, especialmente en Ramiro Ledesma Ramos cuya "noción de Imperio se identificaba con una mayor carga política y revolucionaria que espiritual" (Delgado, 1988: 32). La lectura de José Antonio Primo de Rivera y su Falange Española, no obstante, amalgama en su discurso fascistizante buena parte de las reflexiones de Maeztu, así como la noción de "unidad de destino" de Ortega y Gasset. La "voluntad de Imperio" de la que hablara José Antonio Primo de Rivera en el punto tercero del programa de Falange en 1934 pasaba, indefectiblemente, por recuperar la influencia perdida sobre Hispanoamérica frente al acechante imperialismo capitalista de los Estados Unidos. ${ }^{5}$

Ya bajo la todopoderosa rectoría del general Franco, alzado como caudillo único del reaccionarismo español, la preocupación por Hispanoamérica no cedió en importancia, si bien sí que se fue adaptando al contexto diplomático internacional. Desde la búsqueda de simples simpatías por la sublevación durante la guerra, a la ambiciosa proyección cultural ideada por el Consejo de la Hispanidad en 1941 en la que España buscaba potenciar su papel de puente hacia América para hacerse valer en la nueva Europa fascista en la que a tenor de las victorias alemanas entonces se creía; para, finalmente, acudir a Iberoamérica como única alternativa diplomática ante el aislamiento internacional sufrido después del giro dado por la contienda mundial en 1942 a favor de los Aliados y sobre todo tras el fin de la misma en 1945.

Si bien la Antología de la poesía hispanoamericana de Leopoldo Panero fue publicada en 1944 y 1945 -con lo que cabría pensar ya en ese giro hacia la "política de la hispanidad" dado en 1942-, el encargo que el astorgano recibiera en 1941 se inscribía en una línea editorial propugnada por la elite cultural falangista desde sus mismos inicios. Aún en guerra, la pamplonesa "Revista negra de Falange", Jerarquía, precedente directo de la madrileña Escorial, lanzaba en su segundo número publicado -octubre de 1937- un ambicioso proyecto editorial en el que la poesía hispanoamericana constituía, explícitamente, una de las principales líneas a

${ }^{4}$ Este pensamiento se encuentra perfectamente definido en los artículos que Maeztu publicara en la revista madrileña y que posteriormente reuniera en su conocida Defensa de la Hispanidad (Madrid, 1934).

5 “América es para España, no sólo la anchura del mundo mejor abierta a su influencia cultural, sino, como dicen los puntos iniciales de la Falange, uno de los mejores títulos que puede alegar España para reclamar un puesto preeminente en Europa y en el mundo", afirma José Antonio Primo de Rivera el 18 de abril de 1935 en Arriba, a la sazón periódico oficial de su partido. 
tratar (Penalva, 2005: 66). Terminada la guerra española, el falangismo cultural canalizará su proyecto "Imperial y asuntivo" a través de la revista Escorial y la Editora Nacional, proyectos en los que Leopoldo Panero ya formará parte sustancial. El tema americano, la necesidad de integrar al continente perdido en el Imperio cultural y espiritual español, se ve reflejado, con distintos matices, en varios editoriales de Escorial durante aquellos primeros meses de la publicación, aún bajo la euforia nacional-sindicalista que las victorias fascistas en Europa alentaban. Así, los editoriales de los números séptimo, onceno -especialmente interesante por matizar la innegable independencia soberana de estos países, aclarando que propugnaban únicamente un hermanamiento cultural y espiritual- y decimocuarto -alentando a los jóvenes americanos a preservar su catolicismo sobre el materialismo liberal norteamericano- de la publicación madrileña redundan en esta comunión cultural entre los países hispanohablantes. Bajo estas directrices de "reconstrucción espiritual" del grupo de Escorial, sazonadas con su propia independencia personal como antólogo -tal y como analizaremos más adelante-, gestó Leopoldo Panero su Antología de la poesía hispanoamericana.

Un cariz completamente diferente tomará el proyecto americanista una vez terminada la Segunda Guerra Mundial, pasándose de la entelequia imperial a la más apremiante necesidad diplomática, dado el bloqueo internacional que pesaba sobre el régimen franquista. La llamada "misión poética" por los países del entorno caribeño ideada en 1949 para romper el hielo y ejercer de avanzadilla cultural, se inscribe de pleno en esta realidad. Era preciso abrir un área de influencia con urgencia y el nexo idiomático con América resultaba fundamental. Sin embargo, la imagen antipática - cuanto menos- de la España de Franco al otro lado del Atlántico complicaba mucho las cosas, al tiempo que la presencia activa de lo más granado de la intelectualidad exiliada española evidenciaba la merma cultural sufrida en la Península Ibérica. Es por ello que el régimen orquestó un viaje por diversos países para presentar los mayores logros poéticos de la década dentro del país, eligiendo como embajadores de esa nueva literatura española a Agustín de Foxá, Antonio de Zubiaurre, Luis Rosales y Leopoldo Panero, desmarcándose en el último momento del viaje Gerardo Diego y José María Valverde. Aquella pionera misión poética comenzó en diciembre de 1949, en Cuba. En aquella isla fueron recibidos por Dulce María Loynaz, anfitriona de García Lorca en 1930. La expedición siguió su rumbo por Puerto Rico, Santo Domingo, Caracas, Bogotá, Costa Rica, Honduras, Nicaragua -con ofrenda floral a Rubén Darío incluida-, México y Nueva York. Antes de partir de esta ciudad norteamericana, los poetas se entrevistaron brevemente con Laura de los Ríos y Francisco García Lorca, quien exigió para ello la ausencia de Foxá. El asunto Lorca no fue secundario en aquella gira americana de los "poetas del régimen". A lo largo de la "misión", algunos recitales fueron interrumpidos con el lanzamiento de huevos podridos y hortalizas a los conferenciantes al grito de “iMueran los asesinos de García Lorca!” (Cabañas, 2011: 703-704). En Cuba, Nicolás Guillén y Juan Marinello responsabilizaron 
directamente a Luis Rosales de la muerte del genial poeta andaluz, defendido en cambio por Dulce María Loynaz.

El gran encargo del régimen a Leopoldo Panero le llegó desde su puesto destacado en el Instituto de Cultura Hispánica. Si en la década de los cuarenta el gran elemento aglutinador de este grupo de poetas amigos fue la revista Escorial, en los cincuenta la mayor parte de ellos encontrarán en el ICH su punto de encuentro, coincidiendo así la parte más sustancial de los iniciadores de Escorial como Laín Entralgo, Rosales, Vivanco, Ridruejo, D'Ory o el propio Panero. Igualmente, el arranque de la revista Cuadernos hispanoamericanos -fundada en 1948- se solapa con la desaparición de Escorial en 1950, trasvasándose lo más destacado de sus redactores. Tanto es así, que Santos Torroella llega a denominar a estos poetas como el "Grupo Cultura Hispánica" (Santos Torroella, 1985: 66). ${ }^{6}$ Esta institución, junto al Ministerio de Asuntos Exteriores y la Dirección General de Relaciones Culturales puso a Panero al frente de la organización de una serie de Bienales Hispanoamericanas de Arte destinadas a reunir a lo más sobresaliente de las artes plásticas que en aquel momento despuntaba en el ámbito hispánico, o al menos de aquellos artistas dispuestos a colaborar con el régimen en su lavado de cara internacional. ${ }^{7}$ La I Bienal se celebró en Madrid y fue inaugurada en la cacareada efeméride del 12 de octubre del año 1951 por el mismísimo Francisco Franco. Tres años más tarde, el 18 de mayo de 1954 fue Fulgencio Batista quien inauguró en La Habana la segunda edición de la Bienal. Con un número inusitado de obras expuestas y artistas participantes, las exposiciones matrices se completaron con giras antológicas por otros puntos del continente americano como diversas ciudades venezolanas, colombianas y dominicanas. Por todas ellas, acompañando la gira y coordinando cada detalle, viajó el poeta de Astorga.

Leopoldo Panero continuó trabajando con el proyecto de las bienales, apostando fuerte por la celebración de la III Bienal Hispanoamericana de Arte en Barcelona, realizada finalmente entre septiembre 1955 y enero de 1956. Sin embargo, el autor de Escrito a cada instante se vio progresivamente desplazado por el nuevo comisario de la DGRC Luis González Robles. Parece ser que las acusaciones sobre Panero de conspirar contra el régimen -realmente el astorgano se entrevistó en su nueva gira americana con varios exiliados y "comunistas" españoles, como su

\footnotetext{
${ }^{6}$ Fue precisamente el ICH quien editó en 1949 dos poemarios fundamentales para este grupo poético, La casa encendida de Luis Rosales y Escrito a cada instante del propio Panero. Otros miembros de este "grupo Cultura Hispánica" -además de los citados Rosales, Vivanco, Panero, Ridruejo o d'Ory- serían los escritores Ricardo Gullón, SánchezCamargo, Masoliver, Foxá, Zubiaurre, José M. ${ }^{a}$ Valverde o el propio Santos Torroella.

7 En contrapartida, se celebraron muestras "contrabienales" por parte de exiliados españoles y artistas americanos contrarios al régimen. Estas réplicas antifranquistas fueron encabezadas por Pablo Picasso. En sentido opuesto, Salvador Dalí se alzó como gran defensor de las Bienales institucionales.
} 
célebre primo Justino de Azcárate-, tal vez lanzadas por el propio González Robles, surtieron su efecto. Los proyectos de este último desde la DGRC y el nuevo rumbo de la política exterior franquista, vuelta de nuevo hacia Europa, relegaron definitivamente a Panero de su lugar prominente como embajador cultural del régimen.

\section{Una lectura estética de Hispanoamérica con fecha de 1945}

Entre aquel joven marxista, entusiasta de los "ismos" hispánicos -creacionismo y ultraísmo-, fraternal amigo de Vallejo y rendido admirador de Neruda en los años treinta; y aquel otro "poeta de estado", embajador cultural del régimen franquista e interlocutor extraoficial de la España interior con el exilio republicano de los cincuenta, media un proceso poco estudiado y difícil de analizar -desde la intimidad propia de una persona sensible como Panero- de "reconversión" política y estética. La Antología de la Poesía Hispanoamericana que publicara entre 1944 y 1945 supone un jalón intermedio en muchos sentidos, más allá de la obvia cronología. Ciertamente, la profunda amistad profesada por dos prohombres de Falange, Luis Felipe Vivanco y sobre todo Luis Rosales, acudieron al rescate de aquel sospechoso político en el complicado año de 1940. Miembro excelso de la sección lírica de Escorial, Panero asumió la formulación espiritual y rehumanizadora de la poética del también llamado "Grupo Rosales". La impronta del comunismo cristiano que tanto le uniera pocos años antes a César Vallejo y el rechazo que Neruda abanderara contra la aséptica "poesía pura" eran fácilmente compatibles con lo más sustancial de la estética propuesta por Escorial. La concepción dada por Panero para su antología de poesía hispanoamericana solo se entiende bajo esta poética unitaria del joven grupo, dibujada en sus pilares maestros en el artículo "Arte humano" de Luis Felipe Vivanco del número inaugural de su revista emblemática, y catalizada a través de los poetas áureos en la antología Poesía heroica del Imperio realizada por el propio Vivanco y su inseparable colaborador Luis Rosales. ${ }^{8}$

En 1941 las dos antologías de referencia realizadas sobre la lírica hispanoamericana en España eran indudablemente la Antología de la poesía hispanoamericana preparada por Menéndez Pelayo con motivo del IV Centenario y publicada en Madrid por Rivadeneyra entre 1893 y 1894; y la más reciente de Federico Onís bajo el título de Antología de la poesía española e hispanoamericana y publicada en 1934 por la Revista de Filología Española. ${ }^{9}$ A ellas se suman por

${ }^{8}$ Sobre este asunto, véase el artículo de Antonio Rivero Machina "Luis Rosales y Luis Felipe Vivanco: una lectura heroica de imperios y desengaños", Castilla. Estudios de literatura, 4 (2013): 157-176.

${ }^{9}$ La antología de Onís despertó las airadas protestas de Juan Panero, el hermano de nuestro protagonista, a propósito de la poca importancia dada a la obra lírica del entonces aclamadísimo en España Pablo Neruda (Gullón, 1985: 82). 
aquellos años algunos florilegios de relieve, como los realizados por Ghiraldo, Montaner y Simón o Miguel Rivas y Juan Balague, entre otros (Arencibia, 2005: 48). En el caso de la antología de Leopoldo Panero, el propio autor declara haber seguido la "monumental" selección de Menéndez Pelayo además de dos antologías más: la América poética de Gutiérrez impresa en Valparaíso en 1846 y la homónima de José Domingo Cortés publicada en París en 1875. El astorgano comenta al principiar su prólogo al primer tomo que "las antologías normalmente asequibles al lector español, o eran muy parciales e insuficientes, o estaban totalmente agotadas" (Panero, 1944: 8). No reserva un juicio negativo, sin embargo, para la antología de Onís, cuya obra califica como "espléndida y minuciosa" (Panero, 1944: 9).

Siguiendo las tesis de Pedro Henríquez Ureña y sus brillantes Seis ensayos en busca de nuestra expresión de 1928, Leopoldo Panero parte de sus presupuestos para reflejar "la voluntad de afirmación continental y el ímpetu de independencia que desde las postrimerías del siglo XVIII y todo a lo largo del XIX, brota, con acento más o menos vibrante y genuino, de las entrañas mismas de los jóvenes pueblos hispánicos" (Panero, 1944: 7). Este repaso de la literatura americana en clave, precisamente, de su independencia no debe sorprendernos. El imperialismo palabra de la que el discurso falangista huía por sus resonancias capitalistas, prefiriendo "Imperio" a secas- propugnado por la retórica franquista era así más de signo espiritual, apelando fundamentalmente al acervo católico e idiomático común, que soberano. En este sentido se dirige el editorial del undécimo número de Escorial, de septiembre de 1941, al que anteriormente hicimos referencia.

Leopoldo Panero apela en sus criterios de edición a un "mínimo de fidelidad histórica y de objetividad literaria" (Panero, 1944: 7) y se acoge a la noción de representatividad para la elección del corpus presentado: "me ha parecido conveniente transgredir varias veces mi propio criterio e insertar, en una proporción prudente, poemas representativos de las diversas nacionalidades hispanoamericanas" (Panero, 1944: 7). Ciertamente, el trabajo del antólogo ante el legado literario nada menos que de todo un continente y en un periodo de algo más de cuatro siglos se presenta, cuanto menos, arduo. Por ello, el astorgano afirma que "este criterio, ecléctico y flexible, era el único posible en la materia". Bajo estos presupuestos de salida, Panero coloca al nicaragüense Rubén Darío como único eje de su antología, siendo el hito cronológico que divide los dos tomos de la obra, subtitulados respectivamente "Desde sus comienzos hasta Rubén Darío" y "Desde Rubén Darío hasta nuestros días". ${ }^{10} \mathrm{El}$ antólogo lo expone muy claro al comienzo

${ }^{10}$ En este sentido, resulta sintomático el subtítulo dado por Gerardo Diego a su célebre Antología poética en honor de Góngora. Desde Lope de Vega a Rubén Dario, Madrid, Revista de Occidente, 1927. La consideración del nicaragüense como auténtico portal de la 
de su prólogo: "para comprender desde una perspectiva moderna la línea continua y viva de esta poesía y su verdadero ciclo creador, hay que llegar justamente hasta Rubén Darío" (Panero, 1944: 8-9).

Como ya hemos apuntado, para el estudio preliminar a su primer tomo, Leopoldo Panero parte de las tesis de Henríquez Ureña y el proceso de americanización literaria, culminada precisamente por Darío. De esta manera, se sostiene que "no es fácil ni importa demasiado asimilar el proceso evolutivo de la lírica hispano-americana al de España o al de cualquier otra nación europea" (Panero, 1944: 9), sino que más bien "conviene seguir su proceso de americanización, ver cómo la lengua poética se afianza y el acento se funde y penetra de intimidad genuina" (Panero, 1944: 10). En esta senda americanista, vemos cómo, si Vivanco y Rosales colocaron a Garcilaso en su respectiva antología de la Poesía heroica del Imperio como símbolo y referente de toda la poesía española, Panero lo menciona para referirse a la poesía americana más asimilada y, por tanto, menos genuina. A propósito de Pedro de Oña y el Canto V de su Arauco domado el astorgano dice que "nos traslada a la vieja y sabrosa enumeración garcilasiana de los elementos de la Naturaleza, y apenas si en algún momento suscita una emoción americana auténtica y verosímil" (Panero, 1944: 12). ${ }^{11}$ No obstante, el momento de mayor apología de la poesía genuinamente americana llega cuando, a tenor de la poesía de aquel continente en los siglos XVI y XVII, se comenta cómo "en esos momentos la literatura española es demasiado fuerte y metropolitana - estamos en pleno Siglo de Oro- para que pueda, fuera de ella y en los límites de su imperio espiritual, fertilizar vigorosamente nada que no dimane de su estilo entrañable y de su ámbito propio" (Panero, 1944: 13). No obstante, y aunque pueda parecerlo, esta lectura en clave americanista no cae en irremediable colisión con los presupuestos defendidos en la Poesía heroica del Imperio de Luis Rosales y Luis Felipe Vivanco, ni con la "política de la hispanidad" practicada en 1944 por el Ministerio de Asuntos Exteriores, que huía ya entonces de despertar recelos imperialistas en las antiguas colonias. No se desdice, sino que al contrario se celebra, la riqueza de la comunidad literaria hispanohablante: "la palabra de Castilla va a extender mágicamente el imperio de nuestro espíritu. Pero llega un momento en que los pueblos de América sienten la necesidad de expresarse anímicamente, de una manera honda y peculiar" (Panero, 1944: 15).

Aquí radica el quid de la cuestión. Darío es el eje vertebrador de la antología por culminar el proceso de americanización de su literatura: "viene a ser su poesía la

modernidad en la poesía hispánica es constante en los miembros más destacados del Veintisiete, con Diego a la cabeza.

${ }^{11}$ Panero, más que la poesía americana de corte garcilasiano, prefiere como lector las "Cartas de relación" de los primeros colonizadores, de las que dice que son "la primera contemplación lírica de la Tierra Firme" (Panero, 1944: 13). 
síntesis suprema de este largo proceso creador de la sensibilidad lírica hispanoamericana" (Panero, 1944: 17). Pero, al mismo tiempo, es el genio nicaragüense la piedra angular de la tan buscada "unidad espiritual" de la poesía hispana: "Cuando en 1888 irrumpe genialmente el poeta de Azul y en 1896 el de Prosas profanas, la poesía general española cobra conciencia de su unidad espiritual" (Panero, 1944: 17). Esta es, realmente, la tesis central defendida por Leopoldo Panero en su lectura.

En cuanto al canon de autores, en el tomo primero el antólogo leonés destaca fundamentalmente a Andrés Bello, del que dice que inaugura una "belleza nueva" (Panero, 1944: 11); José María Heredia, "triunfo pleno del romanticismo" (Panero, 1944: 12); Gutiérrez Nájera, "primero que de una manera suficiente, vívida y auténtica, consigue comunicar al lenguaje poético ese son de inocencia y misterioso toque de personalidad" (Panero, 1944: 16); y José Martí, destacado por su "sencilla, fervorosa e intensa poesía" (Panero, 1944: 17). No obstante, los poetas con más poemas antologizados son -además del citado Manuel Gutiérrez Nájera con ocho poemas-: el colombiano José Asunción Silva con ocho piezas; el mexicano Francisco A. de Icaza con nueve; y el cubano Julián del Casal con doce composiciones, el que más de todo el tomo.

El segundo tomo de la Antología de la poesía hispanoamericana, publicado ya en el año 1945, se muestra más interesante por la contemporaneidad de sus poetas seleccionados y la latencia de todo tipo de cuestiones estéticas, políticas y personales. En línea con la Poesía heroica del Imperio de Vivanco y Rosales de 1940 y 1943 respectivamente, el prólogo al segundo volumen de Panero destila igualmente algunas nociones estéticas programáticas, conscientes o inconscientes, de la poética perseguida por los de Escorial. También se distingue el prefacio a este segundo tomo por articular un discurso que incide de manera mucho más marcada en la presupuesta unión hispánica, poniendo el acento -al contrario que en el tomo anterior- en lo que une a toda la poesía escrita en español frente a lo que le separa. En realidad, Panero no hace sino retomar el hilo por donde lo dejó, ya que es según su disertación Rubén Darío quien cataliza la unión de todas las poéticas hispánicas. No obstante, se podría especular con un cambio de matiz en sus apreciaciones surgido tal vez tras un toque de atención institucional o, más probablemente, tras largas y nocturnas charlas junto a Rosales y Vivanco sobre el asunto. En cualquier caso, este Panero del segundo prólogo parece más cercano al que en 1953 entrará en polémica con Pablo Neruda desde los versos de su Canto personal.

Ciertamente, el tono y el discurso del prefacio al segundo volumen de la Antología de la poesía hispanoamericana se muestra, ética y estéticamente, estrechamente emparentado con los prólogos de Luis Felipe Vivanco y Luis Rosales a sendos volúmenes de Poesía heroica del Imperio. Así sucede en su terminología y cosmovisión poéticas: "espíritu", "humano", "íntimo", "cristiano/católico", y "corazón" son los referentes semánticos de los tres prologuistas. Las referencias que Panero realiza sobre fray Luis, san Juan de la Cruz o Keats -a las que el astorgano 
suma con especial devoción a Jorge Manrique, Bécquer, Baudelaire, Shelley y Rimbaud-, y por supuesto Garcilaso de la Vega, se aclimatan programáticamente a las reflexiones de sus grandes amigos Luis y Luis Felipe. Al mismo tiempo, las reflexiones sobre Antonio Machado y Federico García Lorca, símbolos dignísimos del martirio republicano, no difieren en demasía de la postura mantenida por sus compañeros de grupo poético, incluyendo al mismo Dionisio Ridruejo.

En lo referente a la unidad de la lírica hispanohablante, Leopoldo Panero se muestra mucho más tajante que en el tomo precedente. Si los jóvenes poetas de Escorial habían otorgado a Garcilaso de la Vega el título de líder y símbolo absoluto de la lírica española -al menos de la digna de ser escrita y leída-, Panero reserva un papel análogo para la poesía del gran vate nicaragüense: "Lo que en Rubén triunfa y culmina es el espíritu hispánico, trasplantado, pero no desarraigado del viejo solar común" (Panero, 1945: VII). Para el antólogo castellano, en lo que a la poesía de Darío se refiere, es el poso ancestral de lo español y lo amerindio lo que dota de auténtica excelencia a su canto: "su verso desnudo no se explica enteramente más que en virtud de su peculiar condición anímica, en la que se fundían entrañablemente lo español y lo indio, lo aborigen y lo virginal, en una trágica síntesis de cristiana ternura" (Panero, 1945: VIII). En esta senda, para Panero solo César Vallejo y Pablo Neruda se aproximan al canto auténtico del autor de Prosas profanas. No en vano, se ha afirmado en varias ocasiones que Darío, Vallejo y Neruda -más que ningún poeta español- fueron las grandes influencias en su propia poesía (Ley, 1970: 549-550). Así, pocas líneas antes de cerrar su prólogo, el poeta leonés afirma que

habrá que esperar varios años hasta que la genuina poesía americana, la poesía espiritual indio-española, aflore de nuevo a la superficie. La nueva veta virginal de esta dolorosa y misteriosa sensibilidad india la encontramos en la atormentada poesía del peruano César Vallejo; algo más tarde, el lirismo eruptivo y apretado de emoción del chileno Pablo Neruda nos acercará otra vez a la verdad más profunda de la poesía (Panero, 1945: XXII).

Al mismo tiempo, así como Vivanco y Rosales se valieron de la poesía áurea para defender su propia poética -literatura "humana" y "trascendente", comprometida con Dios y con sus compatriotas-, Leopoldo Panero deja entrever su concepción estética personal para la lírica, enmarcada en las líneas maestras de la poética Escorial. Si el que será autor de Escrito a cada instante elige a Rubén Darío como dechado de toda la poesía hispánica, no es, precisamente, por su vertiente modernista de virtuosismo técnico y musical, "sino por lo que guarda de antiguo y vernáculo" (Panero, 1945: VII). La "poesía espiritual indio-española" de la que habla el astorgano radica, más que en el Darío de Azul, en el autor de los Cantos de vida y esperanza. "Lo que es efímero y envejece dentro de su obra es el modernismo de la palabra y no la antigüedad del espíritu" (Panero, 1945: VII), se 
llega a decir. Contrapone Panero dos Darío, pero latiendo siempre en ambos lo más vital de su poesía: "detrás del Rubén inmediato, transparente, tópico, amanerado y afrancesado, queda siempre este otro, humilde, inocente, infantilmente abandonado en medio de su propio y viril dolor" (Panero, 1945: X). Es por ello que el antólogo reivindica el Rubén menos estudiado, el "humano" e "hispánico", sobre el "amanerado y afrancesado". Casi como lema para su propia poética, afirma el vate de Astorga que "la verdadera poesía lírica es, antes que nada, el hada eternizadora, el genio benévolo del corazón humano en el fluir temporal de nuestra vida" (Panero, 1945: X).

No obstante del papel preponderante dado a Darío como gran crisol de la poesía hispánica, no desplaza a Garcilaso de la Vega como gran símbolo del joven grupo poético de Escorial. Panero rinde el vasallaje debido al reconocer que "no es Rubén, seguramente, el poeta capital, el auténtico gran poeta lírico, a la manera que lo son, por ejemplo, fray Luis, San Juan o Garcilaso" (Panero, 1945: XII). Sí se reivindica, empero, el papel referente del nicaragüense en la poesía contemporánea española: "la poesía de Rubén Darío ejerce, como es bien sabido, una influencia capital sobre toda la lírica posterior de América (...), también en la de España" (Panero, 1945: XIV). Menciona Panero a los Machado, Juan Ramón Jiménez o Villaespesa, situando al cabo de esta genealogía de "parentesco espiritual profundo", significativamente, a Federico García Lorca. La lectura ejercida sobre el granadino se adecua al discurso integrador e intencionado de Escorial, destacando Panero del autor de Romancero gitano su "honda y limpia voz popular" (Panero, 1945: XV), sobrepujando ante todo "el prestigio de su brava y jugosa españolidad, de su español entendimiento y señorío, de su racial temperatura poética, de su total amor y conocimiento de nuestra dramática y épica entraña" (Panero, 1945: XV$\mathrm{XVI})^{12}$. Se insiste pues en la misma lectura "españolista" y colectivista que hicieran Vivanco y Rosales de la poesía áurea, inspirada en último término en la retórica falangista. Volviendo a Darío, como símbolo escogido para toda la poesía hispanoamericana, se le define por "la íntima fuerza de su entrañado sentir colectivo, la vitalidad y reciedumbre de su alma india españolizada y espiritualizada por el amor" (Panero, 1945: XVI).

En cualquier caso, el fragmento que más se aproxima a los prefacios publicados por Vivanco y Rosales en su antología de la Poesía heroica del Imperio llega cuando Panero concluye a propósito de Rubén Darío que "en muchos momentos de su obra mejor, Rubén es más bien un poeta épico que un poeta lírico; es decir, más

12 La misma perspectiva sobre el poeta de Fuente Vaqueros quedará ampliamente expuesta por el astorgano en su poema "España hasta los huesos", incluido en su central poemario Escrito a cada instante de 1949. Se reivindica en esta elegía al granadino en cuanto pura esencia del genio español: "de la España mejor nos trae tu canto/ sal de Dios en la ola" (Panero, 1973: 207). 
bien un poeta que encarna y sustancia mágicamente el destino y el íntimo sentir de un pueblo" (Panero, 1945: XVIII). La filiación con la lectura "heroica" y falangista ejercida por Vivanco y Rosales sobre la poesía del Siglo de Oro es si cabe más evidente cuando se añade que "lo que entiendo por épico en Rubén Darío es el anhelo espiritual de afirmación hispánica que su inspiración trasmite" (Panero, 1945: XVIII). Partiendo de estas líneas, resulta menos sorprendente la disputa entablada apenas ocho años después entre el Canto general de Neruda y el Canto personal de Panero.

Conviene matizar que reducir las posiciones de uno y otro a la noción de "leyenda negra" y "leyenda rosa", respectivamente, no hace plena justicia al matiz de sus mensajes. En el caso del astorgano, particularmente, no se niega el genocidio. Lo que se defiende, a cambio, es su valor inmaterial, su trascendencia espiritual para la conformación definitiva de lo americano, que Panero valora, en último término, positivamente. En el prólogo a su antología, dice el vate leonés que:

hay una épica - precisamente americana, precisamente adherida al sentir indio- que consiste en la poética adivinación del pasado ancestral, en la sublimación heroica de las razas aborígenes, en la espiritualización elegíaca de los pueblos que quedaron sumergidos bajo la dominación española (Panero, 1945: XVIII).

Precisamente, esa elegía ancestral es la que aspira a ofrecer Pablo Neruda cinco años después cuando en 1950 publica su Canto general. Sin embargo, todo lo que en Panero deviene en un resultado positivo y asuntivo, en una comunidad espiritual mayor, la "hispanidad"; en el nobel chileno se tiñe de materialismo histórico y denuncia indigenista. No hay lugar para la gloria española en sus versos: "A Veracruz va el viento asesino./ En Veracruz desembarcan los caballos./ Las barcas van apretadas de garras/ y barbas rojas de Castilla./ Son Arias, Reyes, Rojas, Maldonados,/ hijos del desamparo castellano,/ conocedores del hambre en invierno/ y de piojos en los mesones" (Neruda, 1990: 147).

Al materialismo histórico y versión "negra" de la conquista hispánica, decide contraponer Panero su espiritualismo poético y su matizada pero finalmente "rosa" visión sobre el asunto. ${ }^{13}$ No son azarosas las citas con las que el astorgano encabeza

13 Sin lugar a dudas, otros motivos, mucho más personales, movieron igualmente a Leopoldo Panero a escribir su Canto personal: carta perdida a Pablo Neruda. El astorgano se vio directamente atacado en versos como los dedicados a la muerte de Miguel Hernández, donde el chileno escribe: "Que sepan los que te mataron que pagarán con sangre,/ Que sepan los que te dieron tormento que me verán/ un día./ Que sepan los malditos que hoy incluyen tu nombre/ en sus libros, los Dámasos, los Gerardos, los hijos/ de perra, silenciosos cómplices del verdugo,/ que no será borrado tu martirio, y tu muerte/ caerá sobre toda su luna de cobardes" (Neruda, 1990: 521). No insistiremos en ello, dado que estos motivos han sido ampliamente explicados ya en múltiples trabajos. 
su Canto personal: García Lorca, Vallejo, la Biblia, Cernuda, Martí, José Antonio Primo de Rivera, y la Epistola Moral a Fabio. Se reivindica así, desde la España de Franco, el derecho -censurado en Canto general por Neruda- a utilizar e invocar la obra de los poetas más auténticamente americanistas -Martí y Vallejo-, así como a los mártires y exiliados de la Segunda República española -Lorca y Cernuda-. En una vuelta de tuerca, se les equipara con la Palabra de Dios, la poesía áurea y la retórica falangista. Nada menos que la apuesta ética y estética defendida por los de Escorial y expuesta, como hemos apuntado, en las antologías de Poesía heroica del Imperio y Antología de la poesía hispanoamericana. Lo que se dirime entre los "cantos" de Neruda y Panero es mucho más que una rencilla política o poética. Es la contraposición de dos lecturas opuestas sobre el legado cultural español e hispanoamericano. ${ }^{14}$ En este sentido, el mayor argumento del astorgano en su apelación al chileno es la de su condición, innegable y irrenunciable, de propiamente hispano: "Tu indianidad difunta reverencio;/ tu fusión con mi sangre (irreparable)/ en tu propia palabra la presencio" (Panero, 1973: 281). Al mismo tiempo, el propio Panero se inviste del mestizaje espiritual otorgado por él a la comunidad poética hispánica: "Nosotros, los celestes de la raza/ (que encabeza Rubén) indioespañola;/ los que a sol de justicia en la terraza/ esteparia, arrimados a su ola/ de eternidad, latimos justicieros" (Panero, 1973: 301).

En clave política más inmediata, conviene reconocerle a la Antología de la poesía hispanoamericana que la Editora Nacional publicó en 1945 la independencia de selección concedida a su antólogo. Queremos destacar con ello la inclusión de una serie de poetas significados con el comunismo e, incluso, activos militantes de la causa republicana española en la aún reciente Guerra Civil. Tal es el caso de Vicente Huidobro, con nueve poemas seleccionados; González Carbalho, con uno; Nicolás Guillén, con dos composiciones; o, a la cabeza de todos ellos, los tan admirados César Vallejo y Pablo Neruda. Es por ello que otras ausencias significativas, como la de Raúl González Tuñón, más que por su significación política, deben ser imputadas a cuestiones personales o criterios particulares del antólogo astorgano. La más o menos soterrada reivindicación de Antonio Machado y Federico García Lorca en las palabras preliminares de Leopoldo Panero, por otra parte, se inscriben en esta misma senda, matizando el aparente "oficialismo" de esta interesantísima y valiosísima Antología de la poesía hispanoamericana de 1945. En cuanto al repertorio seleccionado, Rubén Darío se destaca con diecinueve poemas. Mismo número de composiciones registra el mexicano Amado Nervo, seguido de

${ }^{14}$ Otro texto capital implicado en la polémica fue el publicado por Gerardo Diego directamente aludido en Canto General, como hemos visto- a través del artículo "Canto personal y polémica general" (El Noticiero Universal, 23 de octubre 1953). Ha sido recientemente editado en Gerardo Diego, Obras completas. Prosa. Tomo VIII, José Luis Bernal (ed.), Madrid, Alfaguara, 2000, pp. 706-708. 
su compatriota Enrique González Martínez con catorce. Destacan así mismo José Santos Chocano, con diez poemas seleccionados; Luis G. Urbina, con una docena; Leopoldo Lugones con diez; Julio Herrera y Reissig con doce; Gabriela Mistral con idéntico número; o Vicente Huidobro con nueve poemas, los mismos que Pablo Neruda. De César Vallejo se recogen once poemas.

A la luz de todo lo expuesto, podemos afirmar que la Antología de la poesía hispanoamericana se presenta como una obra altamente significativa para comprender la relación de los poetas de Escorial, en general, y de Leopoldo Panero, en particular, con la lírica ultramarina, habida cuenta de su representatividad tanto política como estética, ética y personal. No debe ser reducido, por lo tanto, a mero jalón intermedio entre el Panero de los años treinta y el autor de Canto personal, ni ser citado como sencilla curiosidad editorial en aquellos años de autarquía y fragmentación política y moral de la literatura española de interior y del exilio. La representatividad de esta antología en sí misma supone, así pues, un valor propio para el estudio del debate literario español e hispanoamericano al mediar el siglo $\mathrm{XX}$.

\section{BIBLIOGRAFÍA}

ARENCIBIA SANTANA, Yolanda.

2005 "Leopoldo Panero y América: una aproximación", Francisco Juan Quevedo García, Germán Santana Henríquez y Eladio Santana Martel (coords.), Con quien tanto quería: estudios en homenaje a María del Prado Escobar Bonilla. Las Palmas de Gran Canaria: Universidad de Las Palmas.

BARRERA LÓPEZ, Trinidad.

2005 "Neruda y los escritores americanos en Caballo Verde para la Poesía", América sin Nombre, 7, pp. 19-25.

BLANC, Felicidad.

1977 Espejo de sombras. Barcelona: Argos-Vergara.

CABAÑas BRavo, Miguel.

2007 Exilio e interior en la bisagra del Siglo de Plata español: el poeta Leopoldo Panero y el pintor Vela Zanetti en el marco artístico de los años cincuenta. Astorga (León): Ayuntamiento de Astorga.

2011 "Los viajes misionarios de la poesía y del arte al Caribe en la diplomacia franquista", Miguel Cabañas Bravo, Amelia LópezYarto Elizalde y Wifredo Rincón García (coords.), El arte y el viaje. Madrid: CSIC.

DELGADO GÓMEZ-ESCALONILLA, Lorenzo. 
1988 Diplomacia franquista y política cultural hacia Iberoamérica (1039-1953). Madrid: CSIC.

GULLÓN, Ricardo.

1985 La juventud de Leopoldo Panero. León: Diputación Provincial de León.

LEY, Charles David.

1970 "Influencia de Pablo Neruda y de otros poetas hispanoamericanos en la moderna poesía de España", Carlos H. Magis (coord.), Actas del Tercer Congreso Internacional de Hispanistas. México: El Colegio de México.

NERUDA, Pablo.

1990 Canto general, ed. Enrico Mario Santí. Madrid: Cátedra.

PANERO, Leopoldo.

1944 Antología de la Poesía Hispanoamericana. Desde sus comienzos hasta Rubén Darío. Tomo I. Madrid: Editora Nacional.

1945 Antología de la Poesía Hispanoamericana. Desde Rubén Dario hasta nuestros dias. Tomo II. Madrid: Editora Nacional.

1973 Obras Completas. Volumen I. Poesías (1928-1962), ed. Juan Luis Panero. Madrid: Editora Nacional.

PENALVA, Joaquín Juan.

2005 La revista Escorial: poesía y poética. Trascendencia literaria de una aventura cultural en la alta posguerra. Tesis de doctorado. Alicante: Universidad de Alicante.

SANTOS TORROELLA, Rafael.

1985 "El vigilante sueño de Juana", Juana Mordó. Por el Arte, com. M. Logroño. Madrid: Círculo de Bellas Artes.

TRAPIELlO, Andrés.

1995 "Leopoldo Panero. Una reconstrucción", Cuadernos hispanoamericanos, 535 (enero 1995), pp. 91-110. 